\title{
Representasi Visual dan Verbal Iklan Mobil "FORD” pada Koran Arab Digital (Semiotik Charles Morris)
}

\author{
Tsaniananda Fidyatul Chafidzoh ${ }^{1}$ \\ ${ }^{1}$ Magister Bahasa dan Sastra Arab, Fakultas Adab dan Ilmu Budaya, UIN Sunan Kalijaga Yogyakarta, \\ Jl. Marsda Adisucipto, Yogyakarta, Indonesia, 55281 \\ Penulis untuk Korespondensi/ E-mail: ninda0330@gmail.com
}

\begin{abstract}
Abstrak - Iklan mobil "FORD" berisi informasi verbal dan visual sebagai bahan promosi selama Ramadhan $1440 \mathrm{H}$. Tujuan dari penelitian ini adalah untuk mengetahui bentuk semantik, sintaksis, dan pragmatis dalam iklan mobil "FORD" pada koran Arab digital. Penelitian ini bersifat deskriptif kualitatif dengan menggunakan analisis model semiotik Charles Morris. Hasil penelitian menunjukkan bahwa pada level semantik, teks verbal mengandung makna denotasi yaitu maksud penawaran dan penjelasan keunggulan promo dan makna konotasi yaitu secara bertahap menggiring pembaca untuk mengambil tawaran yang disajikan. Pada representasi visual, ada upaya menautkan format iklan dengan referen. Pada level sintaksis, pembuat iklan memperhatikan pemilihan jenis kata dan bentuk kalimat agar runtut dan teratur. Secara visual, ada kaitan antara unsur visual dan teks, seperti pemilihan gambar lampion dan bayangan masjid. Pada level paragmatis, hubungan antara tanda dengan makna tanda tergambar dari kepaduan antara unsur verbal dan visual teks iklan. Iklan ini menyampaikan pesan "Belilah jenis terbaru dari mobil "FORD" pada bulan Ramadhan ini karena anda akan untung. Jangan sampai promo ini terlewat."
\end{abstract}

Abstract - The purpose of this study is to find out the semantic, syntax, and pragmatic forms of the "FORD" car advertisements on digital Arabic newspapers during the month of Ramadhan 1440H. This research is qualitative descriptive by using the Semiotic model analysis of Charles Morris. The results showed that at the semantic level, the verbal text contains the meaning of denotation which is the meaning of bidding and the explanation of the advantages of the offer and the meaning of connotation is to gradually lead the reader to take the offer presented. In visual representation, there is an attempt to link ad formats with referrals. At the syntax level, the ad creator pays attention to the selection of the word type and the sentence shape to be sequential and orderly. Visually, there is a link between the visual elements and the text. At the pragmatic level, the relationship between the mark and the meaning of the marks is engraved from the mix between the verbal elements and the visual text of the ad. These ads convey the message "buy the latest type of FORD cars" in this month of Ramadan because you will be profitable. Don't miss this promo."

Keywords - Iklan, Mobil “FORD”, Semiotik, Charles Morris, Koran digital.

\section{PENDAHULUAN}

$\mathrm{P}$ ada awal abad 20 pengkajian mengenai "tanda" semakin mendapat perhatian di dunia akademik. Seorang filsuf Amerika kelahiran tahun 1901 berusaha untuk memperkenalkan ilmu tentang tanda atau "semiotika" sebagai cabang ilmu pengetahuan. Dialah Charles William Morris, yang mengakaji teori tanda setelah Ferdinand de Saussure. Mulai tahun 1938 ia telah melahirkan karya tentang semiotika melalui bukunya "Teori Tanda". Kemudian menyusul karya-karyanya seperti "Tanda, Bahasa dan Perilaku" (1946), "The Open Self" (1948), "Signifikasi dan Signifikansi" (1963), dan tulisan-tulisan pada Theory of Signs (1971).

Teori tanda versi Morris berkembang di negaranegara Anglo Saxon dan juga dipergunakan oleh ahli semiotik dari Jerman, seperti Bens dan Klaus. [1] Tanda dapat dibagi menjadi dua jenis, sesuai dengan apakah mereka dapat ditafsirkan atau tidak untuk menandakan tanda-tanda lain. "Sinyal" tidak ditafsirkan untuk menandakan tanda-tanda lain, 
tetapi "simbol" ditafsirkan untuk menandakan tanda-tanda lainnya. Semua tanda adalah sinyal atau simbol, kata Morris. Sinyal tidak dapat digunakan sebagai pengganti untuk tanda-tanda sinonim, tetapi simbol dapat digunakan sebagai pengganti untuk tanda-tanda sinonim. Morris memformulasikan teori tanda dalam pengertian behavioristis.

Hal ini berarti bahwa objek penelitian semiotik adalah suatu sikap (behavior) yang dapat diamati, yang dapat dipahami sebagai reaksi makhluk hidup atas rangsangan. Dengan kata lain, objek penelitian semiotik adalah sikap suatu tanda. Objek-objek yang menyebabkan makhluk hidup bereaksi atas suatu tanda yang merujuk pada sesuatu, oleh Morris disebut sebagai "denotatum".

Dalam rangka mengembangkan teori tanda dari Peirce, Morris membagi semiotik menjadi tiga lapis, yaitu pragmatik (pragmatics), semantik (semantics), dan sintaktik (sintactics). [2] Pembagian semiotik Morris ini, didasarkan atas proses terbentuknya tanda atau semeiosis, yaitu wahana tanda, designatum atau apa yang diacu oleh tanda, dan interpretan atau efek tanda itu pada penafsir atau interpreter. [3]

Pendekatan model semiotik Morris ini dianggap cocok dan dapat digunakan sebagai pendekatan untuk menganalisis dan mengevaluasi dokumendokumen yang menjalankan fungsi komunikasi teknis seperti teks berita, brosur, pamflet, bahkan iklan.

Beberapa penelitian terdahulu memanfaatkan dan menerapkan model semiotik Morris ini pada berita untuk mengukur profesioalisme jurnalis, hingga brosure. Meiselina Irmayanti meneliti "Profesionalisme Jurnalis Media Online: Analisis dengan Menggunakan Semiotika Charles Morris". [4] Ia melakukan pengamatan terhadap teks berita sebanyak 1149 berita asli dari tiga situs (Detik.com, Kompas.com, dan Republika.co.id) yang merupakan karya jurnalistik sekaligus bukti gambaran kinerja jurnalis. Teori yang digunakan sebagai pisau analisis adalah teori deontologis. Berdasarkan pengamatan pada aspek sintaktik dan semantik, hasil penelitian menunjukkan bahwa bahasa digunakan oleh jurnalis untuk mengelabui pembaca dan memenuhi kepentingan pemilik baik kaitannya dengan sektor ekonomi maupun politik. Selain itu, jurnalis juga menghilangkan hak klarifikasi pihak-pihak yang terkait fenomena yang menjadi pemberitaan di media online.
Penelitian sebelumnya dilakukan oleh Jiang-Ping Fandengan judul "Charles Morris's Semiotic Model and Analytical Studies of Visual and Verbal Representations in Technical Communication”. [5] Dalam artikel ini, penulis menunjukkan bahwa model semiotik yang diusulkan oleh Charles Morris memungkinkan kita untuk mengoptimalkan pemahaman kita tentang praktik komunikasi teknis dan memberikan poin penyelidikan yang baik. Penulis mencontohkan pendekatan semiotik dalam komunikasi teknis dan menguraikan model Morris dengan menganalisis elemen visual dan verbal dari brosur komunikasi teknis pada tingkat semantik, sintaksis, dan pragmatis. Hasil penelitian menunjukkan bahwa model semiotik Morris dapat menjadi alat teoretis dan praktis yang nyata untuk membantu praktisi dan peneliti mempelajari dan menganalisis penggunaan elemen visual dan verbal dalam komunikasi teknis.

Oleh karena itu, pada tulisan ini penulis akan melakukan penelitian yang bersifat deskriptif kualitatif pada iklan mobil "FORD" yang ada dalam koran digital Arab "Al-Jazirah" edisi Ramadhan $1440 \mathrm{H}$. Hal ini dianggap menarik karena produsen mobil dalam memasarkan mobil memilih momentum bulan Ramadhan, sehingga hipotesis yang berkembang adalah besar kemungkinan narasi yang dibangun dalam iklan mobil tersebut mengandung unsur yang berkaitan dengan Ramadhan. Adapun pertanyaan yang hendak dijawab melalui penelitian ini adalah bentuk-bentuk semantik, sintaktik, dan pragmatik yang terepresentasi baik secara visual maupun verbal dalam iklan mobil "FORD" pada koran digital Arab.

Di samping hal itu, hal menarik lain selain dari sisi momentum kemunculan iklan mobil pada bulan Ramadhan adalah bahwa iklan mobil belum pernah dianalisis atau didekati dengan pendekatan semotik Charles Morris. Penelitian-penelitian semiotik terhadap iklan mobil yang berkembang cenderung menggunakan semiotik Charles Sanders Pierce, Roland Barthes, Ferdinand de Saussure, Scollon and Scollon's maupun yang lainnya. Maka dari itu, keberadaan tulisan ini akan memperkaya sekaligus mengupdate kajian ilmiah semiotik yang menerapkan model Charles Morris, khususnya pada teks iklan.

Berikut adalah beberapa penelitian semiotik terdahulu terhadap iklan mobil. Marwah Firas A. A Al Rawe dalam thesisnya berjudul A SocioSemiotic Study of English and Arabic Shopfront 
Advertising Signs (2018). [6] Ia mengidentifikasi dan mengeksplor pengaruh dari realita sosiokultural dan asumsi bahasa Inggris dan Arab terhadap teks verbal dan visual yang mengonstruksi tanda-tanda dalam iklan Shopfront. Penelitian dilakukan dengan mengacu pada gabungan teori multimodal sosial semiotik dari Kress dan val Leeuwen's (2006), dengan geosemiotics dari Scollon dan Scollon's (2003) dan kerangka semiotik Danesi (2002).

Selanjutnya, yaitu penelitian iklan mobil dalam Harian Jawa Pos oleh Rosyida (2017). [7] Dengan menggunakan semiotik Saussure, Rosyida menyimpulkan bahwa dalam iklan mobil di Harian Jawa Pos tersebut mengandung macam-macam tanda figuratif yang berfungsi untuk mempengaruhi konsumen agar mau membeli produk yang ditawarkannya.

Penelitian terhadap iklan mobil menggunakan semiotik juga telah dilakukan oleh Tjandradipura (2017) dengan mengacu pada model semiotik Pierce. [8] Data yang diteliti yaitu iklan mobil Cherry QQ. Poster iklan mobil Cherry QQ disimpulkan oleh Tjandra berhasil mengomunikasikan makna-makna melalui pesan dalam tanda bahasa sebagai kendaraan roda empat yang hemat konsumsi bahan bakar dan ramah lingkungan.

Dari paparan beberapa hasil penelitian di atas tampak bahwa iklan mobil sudah banyak dikaji secara semiotik namun masih jarang yang memanfaatkan model semiotik Morris.

\section{METODE}

Penelitian ini bersifat deskriptif kualitatif. Yaitu bahwa penelitian ini berisi paparan gejala-gejala kebahasaan sesuai fakta kebahasaan dan uraian bagian-bagian tertentu dari sistem bahasa yang digunakan pada satu waktu tertentu dengan tujuan tertentu. [9] Langkah penelitian dimulai dari pengumpulan data dengan menggunakan metode simak dan teknik catat. Kemudian tahap memilih dan memilah data. Selanjutnya, data yang telah diklasifikasikan tersebut dilakukan analisis semantik, sintaktik, dan pragmatik sesuai model semiotik Charles Morris. Pendekatan semiotik digunakan untuk menguraikan unsur-unsur pembangun iklan dari perpaduan visual dan verbal yang merepresentasikan makna iklan. Hasil analisis disajikan secara informal dalam bentuk uraian.

\section{HASIL DAN PEMBAHASAN}

\section{Teks Iklan}

Secara umum orang awam mengatakan iklan adalah ,jualan ee atau usaha menjual produk, barang atau jasa kepada khalayak. Dyer [10] menyatakan "... advertising mean drawing attention to something or notifiying or informing somebody of something. Sementara Wright (melalui Liliweri) [11] mengatakan "iklan" merupakan alat pemasaran yang persuasif dan sangat penting untuk maksud menjual atau membeli, baik barang (produk) maupun jasa, baik kepada khalayak umum maupun kalangan tertentu saja. Informasi persuasif umumnya menggunakan kata-kata (bahasa tulis) dan disertai dengan gambar agar pembaca tertarik (persuasi) dan mengikuti ajakan pengiklan. Jadi, iklan adalah suatu usaha untuk memberikan informasi, meyakinkan atau membujuk orang banyak melalui bahasa dan disertai gambar ilustrasi agar calon konsumen menyukai, memilih, dan kemudian membeli barang yang sedang diiklankan. [12]

Penampilan iklan komersial melalui media memiliki unsur verbal (kebahasaan) dan unsur nonverbal (luar bahasa) seperti tampilan visual. Unsur kebahasaan (verbal) atau bahasa tulis digunakan karena dianggap lebih efesien, tidak mengenal batasan ruang dan waktu serta dapat menjangkau jauh lebih banyak pembaca daripada bahasa lisan yang terbatas, kecuali melalui radio atau televisi. [13]

Unsur pembangun yang lain adalah unsur nonverbal, yaitu berupa konteks budaya atau kebiasaan-kebiasaan yang dimiliki oleh masyarakat (pada umumnya) ataupun masyarakat sasaran pengguna produk yang diiklankan. Unsur ini dalam iklan direpresentasikan berupa ilustrasi, gambar, dan sebagainya. berikut adalah iklan mobil "FORD" yang ada pada koran digital Arab AlJazirah: 


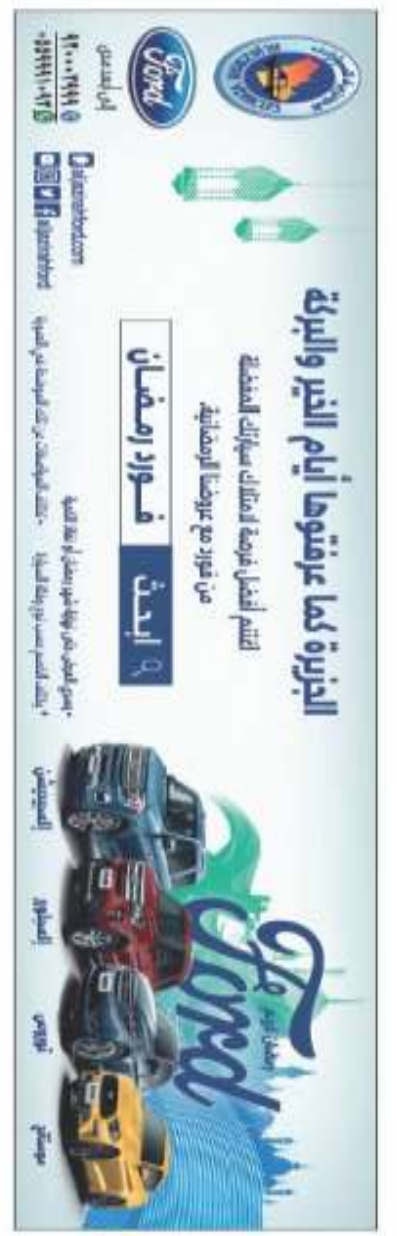

Gambar 1. Visualisasi iklan mobil "FORD”

\section{Model Semiotik Morris}

Morris secara detail mendefinisikan sintaks, semantik, dan pragmatika sebagai berikut. [14] Pragmatik menyepakati asal usul, penggunaan, dan dampak dari tanda-tanda dalam perilaku penafsir tanda, dan dengan demikian memiliki cakupan terluas dari studi semiotika. Semantik mencakup hubungan antara tanda dan objek ditandai, mempersempit studi semiotik dengan makna literal yang ketat dari tanda dan proposisi. Sintaktis menyangkut hubungan formal antara tanda-tanda itu sendiri, aturan logis dan gramatikal yang mengatur penggunaan tanda.

Selanjutnya, tiga faktor perilaku masuk, faktor penentu, penilai, dan preskriptif, ditemukan dalam berbagai tingkat dalam semua komunikasi. Hanya bahasa yang paling halus dan canggih yang memudahkan penggunaan tanda hanya untuk satu atau faktor lain, dan penggunaan semacam itu sangat bergantung pada konteks sosial. [4]
Tabel 1. Klasifikasi dan Identifikasi berdasarkan model semiotik Morris.

\begin{tabular}{|c|c|c|c|}
\hline No. & Lapis Semiotik & Tanda & Maksud \\
\hline 1 & Semantik & $\begin{array}{l}6 \text { kalimat } \\
\text { dalam teks } \\
\text { iklan }\end{array}$ & $\begin{array}{l}3 \text { kalimat } \\
\text { pertama } \\
\text { mengandung } \\
\text { maksud } \\
\text { penawaran } \\
\text { dan } 3 \\
\text { kalimat } \\
\text { selanjutnya } \\
\text { mengandung } \\
\text { perincian } \\
\text { dan } \\
\text { ketentuan } \\
\text { bagi calon } \\
\text { pembeli }\end{array}$ \\
\hline 2 & Sintaktik & $\begin{array}{l}1 \text { kalimat } \\
\text { pertama } \\
\text { berstruktur } \\
\text { kalimat } \\
\text { nominal } \\
\text { dan } 5 \\
\text { kalimat } \\
\text { selanjutnya } \\
\text { berstruktur } \\
\text { kalimat } \\
\text { verbal }\end{array}$ & $\begin{array}{l}1 \text { kalimat } \\
\text { pertama } \\
\text { mengandung } \\
\text { maksud } \\
\text { perkenalan, } \\
2 \text { kalimat } \\
\text { selanjutnya } \\
\text { menuntut } \\
\text { pembaca } \\
\text { melakukan } \\
\text { gerakan dari } \\
\text { visual ke } \\
\text { kegiatan } \\
\text { konkret dan } \\
3 \text { kalimat } \\
\text { terakhir } \\
\text { mengandung } \\
\text { makna } \\
\text { penjelasan } \\
\text { informasi } \\
\text { umum } \\
\text { terkait mobil } \\
\text { "FORD" } \\
\text { yang } \\
\text { ditawarkan }\end{array}$ \\
\hline \multirow[t]{2}{*}{3} & Pragmatik & Teks iklan & $\begin{array}{l}\text { Menandai } \\
\text { referen } \\
\text { jenis-jenis } \\
\text { mobil } \\
\text { "FORD"; }\end{array}$ \\
\hline & & $\begin{array}{l}\text { Struktur } \\
\text { iklan }\end{array}$ & $\begin{array}{l}\text { Mewakili } \\
\text { maksud } \\
\text { pembuatan } \\
\text { iklan dan } \\
\text { penawaran } \\
\text { yang } \\
\text { diberikan. }\end{array}$ \\
\hline
\end{tabular}


Semiotik Lapis Semantik

Ruang lingkup semantik membahas relasi antara tanda dan benda yang ditandai. Istilah denotasi dan konotasi digunakan untuk menggambarkan hubungan antar kedua hal tersebut. Denotasi menggambarkan hubungan langsung sedangkan konotasi menunjukkan variasi hubungan makna dari tanda yang didalamnya mencakup sosial, budaya, ideologi, dan makna emotif dari tanda tersebut.

Pada teks iklan mobil "FORD" edisi Ramadhan tersebut terdapat 6 (enam) kalimat. keenam kalimat ini menjadi tanda untuk memaknai yang ditandai. Berikut urutan kalimat yang disajikan dalam iklan:

$$
\text { 1. الجزيرة كما عرفتوها أيام الخير والبركة }
$$

\section{Al Jazi>ratu kama> 'araftuha> ayyamul-khairi} wal-barakati

- Promo menarik lagi dari Al-Jazirah di bulan yang penuh berkah

$$
\text { 2. عروضنا الرمضنم أفضـل فرصـة لدمتلـدك سيارتك المفضـلة مـ فورد مـع }
$$

\section{Ag\{tanim afd\{alu furs\{atin lidamtalika} sayyarataka al-mufad\{d\{alah min FORD ma'a 'urud\{una> ar-Ramad\{aniyyah

- Jangan sampai terlewat tawaran menarik untuk segera miliki mobil FORD kamu dari promo terbaik kami di bulan Ramadhan ini.

\section{Ibh\{ats FORD Ramad\{an}

$$
\text { 3. 3 ابحث فورد رمضان }
$$

- Carilah "FORD Ramadhan”.

$$
\begin{aligned}
& \qquad 4.4 \\
& \text { Yasriy al-'ardhu h\{atta niha>yati syahri } \\
& \text { Ramad\{an aw nafa>z/ul-kammiyyah }
\end{aligned}
$$

- Promo berlaku selama bulan Ramadhan atau selama persediaan masih ada.

$$
\text { 5. يختلف الخصم حسب نوع وفئة السيارة }
$$

Yah\{taliful-khasmu h\{asba nau'in wafi'ati assayyarah

- Tersedia dalam penawaran harga khusus untuk masing-masing jenis produk mobil.

\section{6. تختلف المواصفات من تلك الموضعة في الصورة \\ Yah\{talifu al-muwa>s\{afa>ti min tilkal- maud\{u'at fi as $\{-s\{u>r a h$}

- Masing-masing jenis produk mobil memiliki spesifikasi khusus sesuai ditunjukkan pada gambar.

Pernyataan dalam iklan yang terdiri dari 6 (enam) kalimat tersebut secara garis besar terdiri dari dua maksud. Maksud menawarkan terdapat pada 3 kalimat pertama. Tiga kalimat setelahnya berisi perincian ketentuan dan keuntungan dari barang yang ditawarkan. Benda yang sedang ditawarkan melalui iklan tersebut adalah 4 jenis mobil FORD keluaran terbaru. Keempat jenis mobil tersebut secara fisiknya merupakan menjadi yang ditandai, yaitu objeknya.

Pada tiga kalimat pertama terdapat ungkapan "kamaa 'araftuhaa", "afdhalu furshatin", dan "ibchats". Ungkapan-ungkapan tersebut secara berurutan memiliki arti leksikal "sebagaimana kalian semua tahu", "kesempatan terbaik", dan "carilah".

Kalimat pertama pada iklan tersebut juga menyebutkan ayyam al-khair wal-barakah untuk merujuk pada bulan Ramadhan yang sedang berlangsung. Ayyam al-khair wal-barakah yang berarti hari-hari yang baik dan penuh barakah ini merupakan bentuk pensifatan terhadap bulan Ramadhan.

Kalimat pertama mengindikasikan makna bahwa lembaga al-Jazirah (Vehicle) memang sering memberikan promo terlebih di bulan Ramadhan. Makna leksikal tersebut kemudian berubah menjadi langsung "Promo menarik lagi". Keberadaan promo ini lalu dipertegas dengan kehadiran kalimat kedua yang menyatakan "promo terbaik" dari perusahaan mobil FORD.

Kalimat kedua diawali dengan fi'il amr'yang mengandung kata "kekinian". Lalu pada kalimat kedua ini juga terdapat pengulangan dari kata yang ada pada kalimat pertama, yaitu penyebutan bulan Ramadhan (walau pada kalimat pertama disebutkan dalam bentuk ungkapan lain). Selain itu, penggunaan kata penyangatan atau ism tafdhil "afdhalu furshatin" ini semakin menegaskan bahwa perusahaan FORD benar-benar sedang menawarkan promo super menarik di bulan Ramadhan dan mengajak masyarakat untuk jangan 
sampai melewatkannya.

Tawaran yang telah disajikan ini lalu diarahkan agar pembaca mencari lebih lanjut sebagaimana cara yang dijelaskan pada kalimat ketiga.

Kalimat ketiga dibuka dengan fi'il amr "ibhats" yang berarti "carilah". Adapun subjek dari kata kerja "carilah" ini mengacu pada kalimat kedua yang disebut pengacuan endoforis yang anaforis. Hal ini karena unsur yang diacu berada dalam teks dan telah disebutkan sebelumnya. Kalimat ketiga ini dikemas dalam bentuk i'jaz dengan penggunaan kohesi gramatikal elipsis. Kalimat ini harusnya "ibh\}ats 'arud\}ana ar-mad\}aniyyah bi kalimat ad-dalaliyyah ford Ramadhan”. Namun subjek pada kalimat ini dielipsis, dengan sumsi pembaca telah mampu memahaminya melalui kalimat sebelumnya.

Secara denotasi, ketiga kalimat tersebut bermaksud penawaran. Adapun secara konotasi, ketiga kalimat tersebut secara bertahap sedang menggiring pembaca untuk mengambil tawaran yang disajikan.

Adapun secara representasi visual pada level semantik ini pembuat iklan mengusahakan agar iklan tersebut saling berkaitan antara format iklan dengan benda yang menjadi referen. Hal ini tampak pada penyajian gambar mobil yang dibuat sama persis perkiraan ukuran dan desainnya dengan tampak aslinya. Lalu, pada masing-masing gambar dilengkapi dengan nama jenis mobil.

Kalimat keempat merupakan ketentuan yan berlaku bagi promo. Kata "al- 'ardhu" berdiri sendiri dengan tidak mencantumkan lagi kata "arramadhaniyyah". Di sini terjadi pelesapan referensi, yaitu kata sifat pada subjek. Hal ini dilakukan dengan asumsi bahwa pembaca telah memahami bahwa kata "al-'ardhu" yang dimaksud itu sama dengan kata "'ardhuna arramadhaniyyah" yang telah disebutkan sebelumnya.

Kalimat kelima dan keenam merupakan keuntungan dari adanya promo Ramadhan ini, yaitu penawaran dengan harga khusus dan penawaran produk unggulan yang masing-masing memiliki spesifikasi yang berbeda dan khusus. Dua kalimat terakhir ini adalah penguatan pernyataan pada kalimat kedua bahwa promo ini adalah "afdhalu furshatin". $\underline{\text { Semiotik Lapis Sintaktik }}$

Level sintaktik membahas hubungan antar tanda yang mana hubungan antar tanda itu bertugas memberikan makna. Dapat kita lihat bahwa pada iklan mobil FORD di atas, 6 kalimat yang ada hanya kalimat pertama yang berjenis jumlah ismiyyah. Adapun lima kalimat setelahnya merupakan jumlah fi'liyyah.

Kombinasi yang digunakan untuk mengawali kalimat berturut-turut adalah ism, fi'il amr, fi'il amr, fi'il mudhari', fi'il mudhari', dan fi'il mudhari'. Satu-satunya nomina yang digunakan untuk memulai kalimat adalah nominan yang menyebutkan nama lembaga pemberi promo, "alJazirah". Kemudian dua kata perintah setelahnya dihadirkan dalam bentuk perintah berjenjang yaitu "perhatikanlah" kemudian dilanjutkan dengan perintah "carilah". Kata perintah pertama hanya menuntut gerakan visual pembaca untuk jangan ketinggalan promo, sedangkan kata perintah kedua sudah meningkat menjadi tuntutan gerakan tindakan.

Tiga kalimat terakhir diawali dengan kata kerja yang mengandung kala sekarang. Ini menunjukkan jenis kalimat deklaratif. Kata kerja pertama bersifat memberikan informasi umum, yaitu tentang masa berlaku promo. Sedangkan kata kerja yang ada pada dua kalimat terakhir bersifat memberikan informasi khusus, yaitu tentang keuntungan yang didapat oleh konsumen dan keunggulan barang yang ditawarkan.

Representasi visual pada level sintaktis ini adalah kesesuaian hubungan antara elemen-elemen visual dengan teks. Pada iklan mobil FORD di atas beberapa elemen penting yang digunakan adalah lampion di samping teks dan bayangan masjid di belakang gambar mobil-mobil yang ditawarkan. Ini merepresentasikan situasi sosial saat teks iklan ini diberlakukan. Elemen lampion di samping teks adalah bentuk cara pembuat iklan menghubungkan antara narasi "ayyamul-khair wal-barakah" dan "ramadhan" kondisi di mana iklan itu diberlakukan, yaitu saat bulan Ramadhan.

Penggunaan elemen lampion ini dikarenakan lampion identik dengan momentum Ramadhan dan hari-hari besar. Elemen bayangan masjid dibelakang gambar mobil-mobil yang ditawarkan ini pun dihadirkan dengan motif yang sama, yaitu menghubungkan antara kondisi sosial yang ada dengan referen yang ditandai oleh teks iklan 
tersebut.

Semiotik Lapis Pragmatik

Level pragmatik berkonsentrasi pada hubungan antara tanda dengan makna tanda tersebut. Kombinasi antara teks verbal dengan elemenelemen visual berpadu menjadikan teks iklan tersebut memiliki makna. Sebelumnya, teks iklan ini adalah tanda yang menandai referen yaitu berupa jenis-jenis mobil FORD yang sedang ditawarkan. Kemudian, struktur iklan yang dibangun itu, menjadi tanda yang melahirkan makna yang diharapkan ditanggapi oleh pembaca. Pada level ini representasi visual fokus pada melengkapi dan memperindah teks sesuai dengan yang dibutuhkan dalam penggunannya.

Pada iklan mobil FORD tampak ada kepaduan antara teks verbal dengan penggunaan elemen visual. Ini merupakan bentuk teks iklan yang bagus karena kepaduannya. Melalui iklan tersebut tergambar maksud bahwa "membeli jenis terbaru dari perusahaan mobil FORD yang bekerjasama dengan lembaga al-Jazirah pada bulan Ramadhan ini adalah keuntungan yang besar bagi pembeli dan jangan sampai promo ini kita sia-siakan agar kita tidak rugi dan ketinggalan."

\section{KESIMPULAN}

Iklan adalah suatu usaha untuk memberikan informasi, meyakinkan atau membujuk orang banyak melalui bahasa dan disertai gambar ilustrasi agar calon konsumen menyukai, memilih, dan kemudian membeli barang yang sedang diiklankan. Iklan mobil "FORD" pada koran digital Arab alJaziirah mengandung unsur verbal dan elemen visual yang didesain sedemikian rupa untuk menarik minat konsumen. Pada iklan tersebut gagasan perusahaan dalam menawarkan produknya disampaikan melalui teks tulisan yang berjumlah 6 (enam) kalimat dan ditunjang dengan berbagai elemen visual.

Berdasarkan model semiotik Charles Morris, hasil penelitian menunjukkan bahwa pada level semantik, terdapat makna denotasi pada teks verbal yaitu maksud penawaran dan penejelasan keunggulan promo. Adapun secara konotasi, teks verbal tersebut secara bertahap sedang menggiring pembaca untuk mengambil tawaran yang disajikan. Secara representasi visual tampak ada usaha untuk mengaitkan antara format iklan dengan benda yang menjadi referen.
Pada level sintaktis, pembuat iklan memperhatikan pemilihan jenis kata dan bentuk kalimat agar runtut dan teratur. Secara visual, ada kesesuaian hubungan antara elemen visual dengan teks, seperti pemilihan elemen lampion dan bayangan masjid.

Pada level pragmatik, hubungan antara tanda dengan makna tanda tersebut tergambar dari kepaduan antara unsur verbal dan visual teks iklan. Melalui iklan tersebut tergambar maksud bahwa "membeli jenis terbaru dari perusahaan mobil FORD yang bekerjasama dengan lembaga alJazirah pada bulan Ramadhan ini adalah keuntungan yang besar bagi pembeli dan jangan sampai promo ini kita sia-siakan agar kita tidak rugi dan ketinggalan."

\section{REFERENSI}

[1] S. Patinnasarany, Elemente der Semiotic diterjemahkan oleh Traubaut, Jurgen dengan judul Dasar-Dasar Semiotik, Jakarta: Pusat Pembinaan dan Pengembangan Bahasa,, 1996.

[2] W. North, Hand Book Of Semiotic, USA: Indiana University Press, 1995.

[3] F. HT, Semiotika 1, Yogyakarta: Diktat FIB UGM, tt.

[4] M. Irmayanti, "Profesionalisme Jurnalis Media Online: Analisis dengan Menggunakan Semiotika Charles Morris," Jurnal Komunikasi Indonesia, vol. III, no. 02, p. 143, Oktober 2014.

[5] J.-P. Fan, "Charles Morris's Semiotic Mdel and Analytical Studies of Visual and Verbal representations in Technical Communication," Journal of Technical Writing and Communication, vol. 36, no. 2, pp. 121-139, 2006.

[6] M. F. A. A. Al-Rawe, A Socio-Semiotic Study of English and Arabid Shopfront Advertising Signs, Baghdad: University of Baghdad, 2018.

[7] I. A. Rosyida, "Analisis Semiotika pada Rubrik Iklan Mobil Harian Jawa Pos," EDUKATA, vol. 2, no. 2, pp. 111-120, 2017.

[8] C. Tjandradipura, "Kajian Iklan Mobil Cherry QQ dengan Pendekatan Semiotik," Jurnal Idealog, vol. 2, no. 3, pp. 263-274, 2017.

[9] S. Muljani, Wacana Iklan "Bank Muamalat" pada Majalah Sabili: Pendekatan Mikrostruktur dan Makrostruktur, dalam Sumarlam (Ed). Teori dan Praktik Analisis Wacana, Surakarta: Pustaka Cakra, 2003. 
[10] G. Dyer, Advertising as Communication, London and New York: Routledge, 1989.

[11] A. Liliweri, Dasar-dasar Komunikasi Periklanan, Bandung: Citra Aditya Bakti, 1992.

[12] M. Masrukhi, "Struktur Iklan Komersial di Media Cetak Mesir," CMES, vol. VII, no. 02, pp. Edisi Juli-Desember, 2014.
[13] G. Keraf, Diksi dan Gaya Bahasa, Seri Retorika, Jakarta: Gramedia Pustaka Utama, 2001.

[14] C. Morris, Foundation of the Theory of Signs. Chicago, III penyunt., Chicago: University of Chicago Press, 1938. 